\title{
A hybrid based genetic algorithm for solving a capacitated fixed-charge transportation problem
}

\author{
Petrica Pop ${ }^{1}$, Oliviu Matei ${ }^{2}$, Corina Pop Sitar ${ }^{3}$ and IoAna Zelina ${ }^{1}$
}

\section{ABSTRACT.}

This paper is focusing on an important transportation application encountered in supply chains, namely the capacitated two-stage fixed-charge transportation problem. For solving this complex optimization problem we described a novel hybrid heuristic approach obtained by combining a genetic algorithm based on a hash table coding of the individuals with a powerful local search procedure. The proposed algorithm was implemented and tested on an often used collection of benchmark instances and the computational results obtained showed that our proposed hybrid heuristic algorithm delivered competitive results compared to the state-of-the-art algorithms for solving the considered capacitated two-stage fixed-charge transportation problem.

\section{REFERENCES}

[1] Antony Arokia Durai Raj, K. and Rajendra, C., A genetic algorithm for solving the fixed-charge transportation model: two-stage problem, Computers \& Operations Resaerch, 39 (2012), 2016-2032

[2] Back, T., Hoffmeister, F. and Schwefel, H.-P., A survey of evolution strategies, in Proc. of the 4th International Conference on Genetic Algorithms, San Diego, CA, July, 1991

[3] Bookbinder, J. H. and Sethi, S., The Dynamic Transportation Problem: A Survey, Naval Research Logistics Quarterly, 1980, 27(1). DOI: 10.1002/nav.3800270107

[4] Chen, S., Zheng, Y., Cattani, C. and Wang, W., Modeling of Biological Intelligence for SCM System Optimization, Computational and Mathematical Methods in Medicine, Article ID 769702, 2012

[5] El-Sherbiny, M. M., Comments on "Solving a capacitated fixed-cost transportation problem by artificial immune and genetic algorithms with a Prüfer number representation" by Molla-Alizadeh-Zavardehi, S. et al., Expert Systems with Applications (2011), Expert Systems with Applications, 39 (2012), 11321-11322

[6] Geoffrion, A. M. and Graves, G. W., Multicommodity distribution system design by benders decomposition, Management Science, 20 (1974), 822-844

[7] Koza, J. R., Concept formation and decision tree induction using the genetic programming paradigm, in Parallel Problem Solving from Nature - Proceedings of 1st Workshop, 1989, 768-774

[8] Lupşa, L., Duca, D. I., Chiorean, I. and Neamiu, L., Dynamic transport problems of cost type and time type, Creat. Math. Inform., 17 (2008), No. 3, 452-459

[9] Matei, O. and Pop, P. C., An efficient genetic algorithm for solving the generalized traveling salesman problem, in Proc. of the IEEE International Conference on Intelligent Computer Communication and Processing, 2010, 87-92

[10] Michalewicz, Z., Genetic algorithms + data structures = evolution programs, Springer Science \& Business Media, 2013

[11] Molla-Alizadeh-Zavardehi, S., Hajiaghaei-Kesteli, M. and Tavakkoli-Moghaddam, R., Solving a capacitated fixed-cost transportation problem by artificial immune and genetic algorithms with a Prüfer number representation, Expert Systems with Applications, 38 (2011), 10462-10474

[12] Pintea, C.-M., Pop Sitar, C., Hajdu-Macelaru, M., and Pop, P. C., A Hybrid Classical Approach to a FixedCharge Transportation Problem, in Proc. of HAIS 2012, Part I, Editors E. Corchado et al., Lecture Notes in Computer Science, 7208 (2012), 557-566

Received: 28.03. 2015; In revised form: 22.10.2015; Accepted: 04.11.2015

2010 Mathematics Subject Classification. 90B06, 92D10, 05 C85.

Key words and phrases. Fixed-charge transportation problem, genetic algorithms, hybrid algorithms .

Corresponding author: Petrica Pop; petrica.pop@cunbm.utcluj.ro 
[13] Pintea, C.-M. and Pop, P. C., An improved hybrid algorithm for capacitated fixed-charge transportation problem, Logic Journal of IJPL, 23 (2015), No. 3, 369-378

[14] Pop, P. C., Generalized Network Design Problems. Modeling and Optimization, De Gruyter Series in Discrete Math. Appl., Germany, 2012

[15] Pop, P. C., Pintea, C. M., Pop Sitar, C. and Dumitrescu, D., A Bio-Inspired Approach for a Dynamic Railway Problem, IEEE Proceedings of the 9th International Symposium on Symbolic and Numeric Algorithms for Scientific Computing, pp. 449-453, IEEE Computer Society Press, Timisoara, Romania, September 26-29, 2007

[16] Pop, P. C., Pintea, C. M., Pop Sitar, C. and Hajdu-Macelaru, M., An efficient reverse distribution system for solving a supply chain network design problem, J. Appl. Logic, Elsevier, Vol. 13 (2015), No. 2, Part A, 105-113

[17] Schaffer, J. R. and O'leary, D. E., Use of penalties in a branch and bound procedure for the fixed transportation problem, European Journal of Operational Research, 43 (1989), 305-312

[18] Sun, M., Aronson, J. E., Mckeown, P. G. and Drinka, D. A., A tabu search heuristic procedure for the fixed charge transportation problem, European Journal of Operational Research, 106 (1998), 441-456

[19] Syarif, A., Yun, Y. and Gen, M., Study on multi-stage logistic chain network: a spanning tree-based genetic algorithm, Computers and Industrial Engineering, 43 (2002), 299-314

[20] Wirth, N., Algorithms and data structures, 1986

1 Department of Mathematics AND InFormatics

TECHNICAL UNIVERSITY OF CLUJ-NAPOCA

North University CENTER AT BAiA MARE

BAIA MARE, ROMANIA

E-mail address: petrica.pop@cunbm.utcluj.ro

E-mail address: ioanazelina@yahoo.com

2 Department of Electrical EngineERING ANd Computer SCIENCE

TECHNICAL UNIVERSITY OF CLUJ-NAPOCA

NORTH UniVERSITY CENTER AT BAIA MARE

BAIA MARE, ROMANIA

E-mail address: oliviu.matei@holisun.com

3 Department of Economics

TECHNICAL UNIVERSITY OF CLUJ-NAPOCA

North University CENTER AT BAIA MARE

BAIA MARE, ROMANIA

E-mail address: corina.pop.sitar@cunbm.utcluj.ro 